\title{
EMPOWERMENT UNDERPRIVILEGED YOUTH IN WEST JAKARTA TO PREPARE A BETTER FUTURE
}

\author{
Ulani Yunus \\ Bina Nusantara University, Indonesia. \\ uyunus@binus.edu
}

\begin{abstract}
There are still underprivileged citizens in Jakarta, even around high-class residences in West Jakarta. The purpose of this research is to find out how the right empowerment for adolescents from underprivileged families in Jakarta, therefore they prepare for their future better than their parents. The concept used is Corporate Social Responsibility and Empowerment. The research method used is the descriptive qualitative. The research subjects were teenagers who registered in the KEJAR SIWALI group, a study group for children from the lower economy because their parents were scavengers and unskilled labourers. Methods of data collection through interviews with KEJAR SIWALI coordinators and five teenagers as informants who attended the research activity were more than five meetings. The results of the study show that the empowerment program for them is to use other teenagers (students of the college) to maintain their ideals to become scholars even till Master or PhD, even though their economic class are less than other teenagers in Jakarta. They are rarely snacking and they want to save money. Basically, they have the enthusiasm to learn to improve the familys economic level, even though they dont know how to finance their lives later. Their aspirations want to be teachers, Civil Servants, Entrepreneurs, Accountant and Doctor. They do not like to see other teenagers, pregnant before marriage and early marriage. The BKKBN program has been successful in this group. Their religious activities were done obedience, and they hope the empowerment in soft skills such as public speaking, IT, accounting and sports.
\end{abstract}

Keywords: Better Future, Empowerment, Underprivileged Youth, West Jakarta

\section{INTRODUCTION}

With the development of the internet at this time began many internet-based companies, especially like fintech, e-commerce, marketplace. With the rapid growth of digital-based business, many people are competing to make digital-based companies that are expected to be able to answer all the challenges that exist with innovations created. Fintech itself, which has an area that can target the market with a target market for business people or B2B (business to business) and also end users or B2C (business to customers).

With current conditions, where the business world is influenced by technology and with the presence of fintech companies in Indonesia, it opens up opportunities for investors to enter the business world easily through investing in fintech companies. Financial technology has several forms such as investment, payment, lending and crowdfunding (Leong et.al, 2017).

Financial technology is one of the most promising business fields in 2016 (Chishti and Barberis, 2016) fintech itself, especially in Indonesia, has several types such as crowfunding, personal finance, lending, retail investment, payments to penetrate into the reimbursement field or platform Expense Management System.

Jojonomic is the first in Southeast Asia that develops digital reimbursement solutions to automate the reporting systemand management expense claim. Jojonomic Pro application is a pioneer in mobile reimbursement technology, cash advance and digital attendance that uses cloud based solutions. For employees and companies, Jojonomic Pro helps make internal processes easier, more practical, fast, transparent, safe, and controlled.

An interview with one of the business developments from the company in the current situation in terms of sales is indeed volatile, Jojonomic's own target is 2 billion each month, but the current sales situation is only 1.5 billion, the data shows that the expected target has not been achieved, and when the enthusiastic pitching given by customers to Jojonomic products is still lacking, because customers are more aware of the brand and value of competitors even though Jojonomic has a value of the product that is in fact better than competitors. So that communication between brands and prospective customers is very important in order to increase public awareness about the Jojonomic brand. As said in (Kotler, 2005) in Tsikirayi, Catherine Mazwi R et al (2013),

IMC produces better communications consistency and greater sales impact. It places the responsibility in someone's hands where none existed before to unify the company's image as it is shaped by thousands of company activities. It leads to a total marketing communications strategy aimed at showing how the company and its products can help customers solve their problems

Conclusion from the above explanation that IMC is able to produce better communication consistency and greater sales impact, IMC itself aims to create a strong brand identity consistently and positively at all points, so 
that an effective IMC (intrgrated marketing communication) program is needed to be able to help increase awareness of potential customers so as to increase interest in using products in the use of Jojonomic products.

The impact of awareness given to the company is very significant so that it can make prospective customers have confidence in Jojonomic better, according to Smith and Wheeler (2002) in Lu, L.-C et al (2014) states that suggest that high brand awareness improves trust in a brand and its advertisements, so it can be said that if prospective customers get a lot of awareness able to increase trust in a brand and also its advertisements. Based on field interviews and supported by previous research findings that branding is important it requires a program that can help improve the brand of both products and companies, this can be done through integrated marketing communication.

By implementing IMC in every communication approach, it can make communication more effective and influence positive attitudes and brand awareness according to Adetunji Raji Ridwan, et al (2014)The Implementation of Integrated Marketing Communication (IMC) Principles in Branding and Advertising: A Conceptual Exploration, This study arguably affirms that the implementation of IMC is any approach or message development method that can be practically used to integrate different message strategies or communication techniques or different communication channels for the purpose of making marketing communication messages more effective and influencing and stipulating positive decisions and attitudes and that accommodate the development of successful brand image and awareness. By maximizing the IMC program a good product will get greater exposure, but this IMC program is not maximized by the company. The lack of public awareness of the Jojonomic brand will have an impact not only on personal selling that is experiencing obstacles but also various kinds of challenges on the ground so that it has the potential to fail or only reach targets that are very minimal. These problems are often encountered during the exhibition.

Jojonomic by maximizing IMC can expand exposure and reach more potential customers so that Jojonomic can be superior to compete with similar companies, according to (Reid et al, 2005) in Muhanji (2015) To survive in the competitive marketing environment, both small and large organizations need to adopt integrated marketing communication practices in order to attract and retain customers hence long term relationships and sales performance and overall productivity which can also be interpreted that to survive in a competitive marketing environment, both small and large organizations need to adopt practices integrated marketing communication to attract and retain customers so that long-term relationships and sales performance and overall productivity

Based on this background this study aims to:

1. Knowing how to evaluate and the effectiveness of the integrated marketing communication program in Jojonomic.

2. To find out how to design a 360 degree communication plan in Jojonomic.

Based on this background this study aims to:

The benefits of this research are:

1. Knowing how to evaluate and the effectiveness of the integrated marketing communication program in Jojonomic.

2. To find out how to design the next 360 degree communication plan in Jojonomic.

3. Become an evaluation material for companies in determining an effective IMC program going forward.

4. Suggestions, thoughts, information and as a reference for strategies to increase sales leads.

\section{The scope of research}

There are some limitations in the issues raised in this thesis. It is intended that the thesis can run according to the scope and focus on the problem. Here are a few restrictions that are set:

1. Research focuses on the business market of Jojonomic financial technology companies.

2. This study discusses imcl programs which include Direct Marketing, Event, Advertising in Jojonomic.

3. The data used is data obtained from PT. JOJO NOMIC INDONESIA.

\section{DESIGN}

In this study using quantitative data type which is sales data and qualitative data is the result of interviews with representatives from Jojonomic, the method of data collection is done through observations made during the internship period from February 2018 to March 2019, interviews were conducted with Jojonomic representatives according to data requirements and library research looking for information needed through books, journals and the internet. 


\section{M's Integrated Marketing Communication Model}

In this case study research using the $6 \mathrm{M}$ analysis model. $6 \mathrm{M}$ is a model for analyzing integrated marketing communication put forward by Richard Luecke in the Harvard Business School book: Marketing Toolkit: the 10 strategies you need to succeed 2006. This analysis model was found by the author in the Carnegie Dartlet blog which is a communications company offering innovative services in the field of research, strategy, creative, digital, and team development, after evaluating the IMC program in Jojonomic, after getting the results effective or not, the solutions provided use 360-degree marketing communication to be able to answer the problem at hand.

1. Market:

Who is the destination? Is it already communicating with the right target and it would be better to compose a message specifically for them, a special message made can make the recipient feel "more" special.

2. Mission:

What objectives do you want to obtain? The message must be focused so that it does not deviate from the final destination, so that potential customers get accurate information.

3. Message:

communicates the core of the message, so there is no need to provide excessive information to potential users so that potential users can find out more about the company by itself

4. Media:

what communication channel will be used to convey the message? Using only one medium is never enough but too much media can pose a risk to potential customers getting inaccurate information.

5. Money: How much funds are allocated and how to combine communication media by maximizing the budget that is owned to get maximum results

6. Measurement:

How can you measure the performance of your campaign? Be sure to prepare a plan to measure the results of each media used so you can find out which media are effective and achieve the specified targets.

\section{Degree Communication Model}

The name "360-degree communication" suggests the presence of all elements forming a coherent whole, which is well illustrated by the shape of the wheel. Consumer is in the middle of the wheel, as he receives advertising messages from all possible channels - online and offline channels (Minib28 : 135).

It can also be interpreted that 360 degree communication has all the elements that are interconnected so that it can be described as shaped like a wheel, consumers who are in the middle are able to get messages from various advertising channels from online and offline. By using this strategy, it is expected that communication limitations faced can expand the communication channels of the company so that it can be easily accepted by prospective customers. Examples of communication channels can be received through advertising, public relations, direct marketing, sales promotion.

Often used by certain brands and advertising campaigns, it gives an extraordinarily different character and distinguishes it from other communication campaigns. Media that can be considered in 360 degree marketing communication is diverse and evolves along with the development of technology and the creativity of creators. Skillful in selecting ways to reach message recipients and the communication tools used must describe harmonious relationships and provide benefits in the form of more efficient communication quoted from Olearnik (2018: 133) The choice of channels and communication tools may include:

1. ATL (above the line): traditional mass media: advertisements on television, radio, press, posters, billboards.

2. BTL (below the line): target certain groups or have determined sales promotion, public relations.

3. Events - direct marketing: email marketing, telemarketing, special events.

4. Interactive marketing activities: Internet advertising, social media tools, marketing in SEM (search engines), mobile marketing and applications, advertising in games, viral marketing, Internet websites 


\section{RESULTS AND DISCUSSION}

\section{Current Condition Results}

The following are the evaluation results using the $6 \mathrm{M}$ Integrated Communication Model analysis based on the IMC program that Jojonomic has conducted

Table 1.1 Direct Marketing evaluation

\begin{tabular}{l} 
Direct Marketing \\
\hline
\end{tabular}

Source : Author 2019

Table 1.2 Advertising Evaluation

\begin{tabular}{|c|c|c|c|c|c|}
\hline \multicolumn{6}{|c|}{ Advertising } \\
\hline \multirow{4}{*}{\multicolumn{3}{|c|}{ 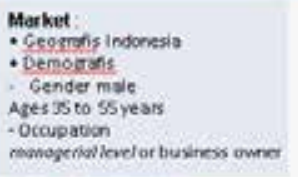 }} & \multicolumn{3}{|l|}{ Moncy } \\
\hline & & & Media & Herpe & Focal \\
\hline & & & $\begin{array}{l}\text { Facubook Ads } \\
\text { instugrm Ads }\end{array}$ & 1.000.000/ hari & Ap $30,000,000$ \\
\hline & & & GoogleAds & so0.000/han & $20,15,000,000$ \\
\hline \multirow{2}{*}{\multicolumn{3}{|c|}{$\begin{array}{l}\text { Media : FacebookAds, } \\
\text { Googichas, 8EO, } \\
\text { instates }\end{array}$}} & Goode Crgarit & $1.000 .000 / \mathrm{kedan}$ & Ap $1,000,000$ \\
\hline & & & Total & & $R, 45,000,000$ \\
\hline \multicolumn{3}{|c|}{$\begin{array}{l}\text { Asssion : Expand marketing. } \\
\text { Comincing the marknt of } \\
\text { Jojonemic. }\end{array}$} & \multicolumn{3}{|c|}{$\begin{array}{l}\text { Message: Comeys the value that Joionomk } \\
\text { has, such as, montoring, controt, growth }\end{array}$} \\
\hline \multicolumn{3}{|c|}{ Aneasiane } & & & \\
\hline \multicolumn{3}{|c|}{ inath } & & & \\
\hline $\mathrm{Nun}$ & Togetensonim & loosinen & & & \\
\hline$\omega$ & $m$ & it & & & \\
\hline 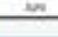 & $=$ & $x$ & & & \\
\hline
\end{tabular}

Source : Author 2019

Table 1.3 Event Evaluation

\begin{tabular}{|c|c|c|c|c|c|}
\hline & \multicolumn{2}{|c|}{ Event } & & & \\
\hline \multirow{7}{*}{ 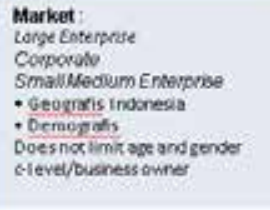 } & \multicolumn{4}{|l|}{ Mossure } & \\
\hline & \multicolumn{4}{|c|}{ tent } & \\
\hline & \multirow{2}{*}{ 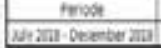 } & tere & and & troniens & \\
\hline & & 3avis & क्ष & 墥 & \\
\hline & \multicolumn{5}{|c|}{$\tan$} \\
\hline & \multirow{2}{*}{$\begin{array}{l}\text { Prid } \\
\text { mentens }\end{array}$} & \multirow{2}{*}{ 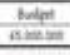 } & Prants & 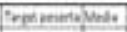 & Ferelinat: \\
\hline & & & $\pi-1$ & i= & \\
\hline $\begin{array}{l}\text { Maxsion : increases sules and } \\
\text { make good image of Jolonomic }\end{array}$ & \multirow{2}{*}{\multicolumn{4}{|c|}{ 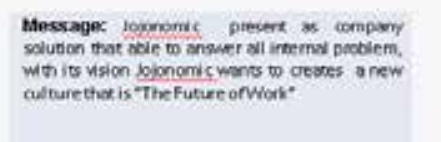 }} & \\
\hline \multicolumn{2}{|l|}{ Media : Exhibtion and Evert } & & & & \\
\hline \multicolumn{6}{|l|}{ Maneny } \\
\hline toen & \multicolumn{2}{|l|}{ fint } & & & \\
\hline 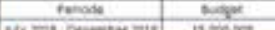 & reose & & & & \\
\hline 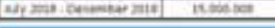 & Nexan & ans & & & \\
\hline
\end{tabular}

Source : Author 2019 
From the results of the evaluation of the current condition, a summary of the overall evaluation of the IMC activities that have been carried out is made Jojonomic.

Table 1.4 Evaluation Summary

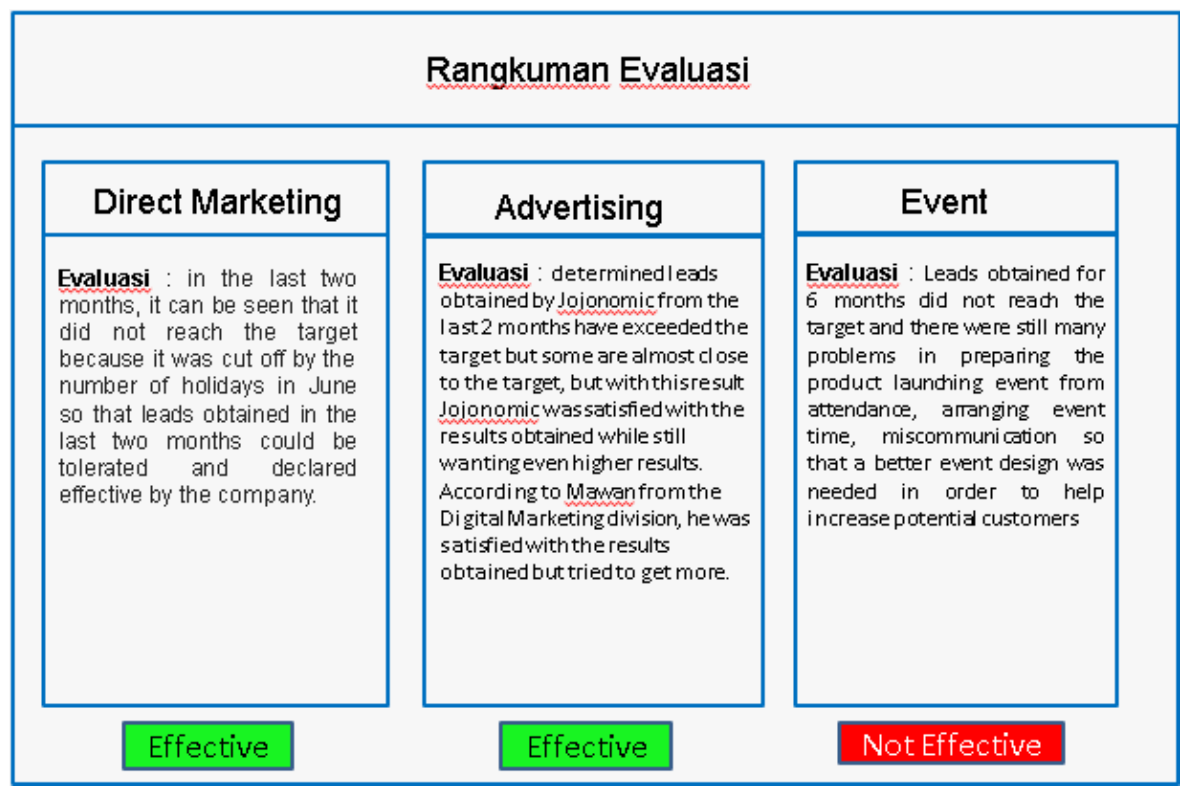

Source : Author 2019

From the results of the evaluation it was found that from the 3 evaluations it was found that Direct Marketing and Advertising conducted by Jojonomic had been effective because the specified target had been achieved while for the event conducted by Jojonomic it had not been effective because Leads obtained for 6 months did not reach the target and there was still a lot happening problems in preparing the event for attendance, arranging event time, miscommunication so that a better event plan is needed in order to help increase potential customers.

\section{0-Degree Communication Model}

\section{Event}

This event was created to educate about working conditions based on digital, presenting speakers who have used Jojonomic to provide testimonials on products, then participants will be given a live product demo to further convince them that Jojonomic products are the solution to their company's problems.

\section{LinkedinAds}

Linkedin is part of TTL (through the line) which is a new term in the marketing world that combines BTL and ATL promotions. Because of the sophistication of information technology that makes ATL and BTL increasingly cryptic, although it can be disseminated on a large scale but is still directed according to the target market that has been set. Because B2B has a specific market here, social media is a part of through the line, and the results of Jojonomic Advertising did show good results but it would be better if Jojonomic also made Linkedin as one of the media to advertise its products because Jojonomic's target is B2B which is Linkedin is a professional platform that is widely used by professional workers as well and adds women as a target from Jojonomic's own advertisements because in 2019 there are already many women who play an important role in a company so that it does not cover the possibility of adding women as Jojonomic advertising targets will increase potential customers so that sales can increase and reach the targets set.

\section{Content Maketing}

Content Marketing includes webinars, blogs, videos can be one of the solutions for companies to present their companies by creating a seminar or creative content, webinars themselves do not need a large budget usually to create an event that requires a large budget for renting space, consumption, media, entertainment, it all requires money and great preparation. The creation of blog or video content can be adapted to current market conditions so that the exposure obtained is greater. Making videos and blogs helps get leads because there are people who like to read but there are also those who like to watch videos with Jojonomic providing these things can increase the chance of getting leads from content created because Jojonomic needs to use all potential channels to get leads. also helps to leave traces on the internet so that people who search for Jojonomic on the internet are also 
able to see jojonomic traces on the internet. According to Järvinen, J.,\& Taiminen, H.(2016) study also showed that integrating content marketing and marketing automation efforts can generate high-quality sales leads and increase efficiency levels by overcoming a cumbersome selection process for prospects (see, e.g., Moncrief \& Marshall, 2005; Trailer \& Dickie, 2006) through automated classification. So content marketing is effective to gain high quality sales leads to increase sales for the company.

\section{Event Sponsorship}

Doing sponsorship does take a lot of funds but many benefits can be obtained through the sponsorship, by sponsoring an event if the promoter will advertise the event, the Jojonomic brand will also be spread, get a special booth with the best space and location so that it is easy to find and attractive, events that can be selected are technology events, startup events, human resource management events

According Russell and Close (2013) in Tomalieh, E. F. (2016) conclude that customers develop more favorable event-sponsor bonds when they like the event. A customer's positive attitude towards the event will influence their perceptions of event-sponsor fit positively, especially for service brands. The study also demonstrates the positive influence of event-sponsor fit on customer's favorable brand commitment to the sponsor's brands, and customers' intentions to buy the sponsor's services. Event-sponsor fit could gain a valuable role in strengthening consumer relationship outcomes.

One of which is a recommended event to be sponsored is the "Indonesia Fintech Show 2019" event. The report from the post event in 2018 showed there were around 3,561 visitors, of all the visitors there were around 2,618 visitors who were interested in using the products offered. Visited from 24 countries and recorded \$ 1.2Billion orders received on the spot by visitors. The results of the post event report showed that following the event the benefits gained were numerous and good for Jojonomic development.

\section{Picture 1.1 Post Even}

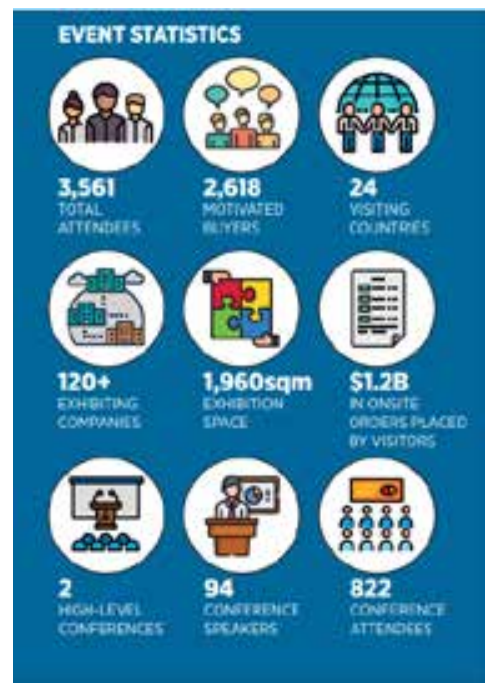

Source : indonesiafintechshow.com

\section{CONCLUSIONS AND SUGGESTION}

\section{Conclusions}

1. Based on the IMC program evaluation results that have been carried out using the $6 \mathrm{M}$ Integrated Marketing Communication Model see that the two IMC programs that have been effective namely Advertising, and Direct Marketing because they have gotten leads in accordance with the targets that have been targeted by the company. However, there is still one program that is not yet effective, namely Events because the targeted leads have not reached the target of 1000 leads, so a program was created to help get leads.

2. Based on the results of the previous evaluation, stated that the event conducted by Jojonomic requires a new design to be able to develop the previous program. For this reason, the Author makes a Billboard design to increase web traffic and awareness. Where this program increases awareness to help get potential customers and after that it is helped to convert to an Event to get an education phase first about the new Jojonomic after which an event is created to increase sales. Jojonomic's activities, on the other hand the Author also suggested Jojonomic to conduct sponsorship at the "Indonesia Fintech Show 2019" event which was very helpful in terms of exposure to awareness and increasing networking and also increasing sales 


\section{Suggestion}

1. After evaluating the IMC program that has been running at the moment advertisement, direct marketing, event shows that the 2 JoConomic IMC activities have been effective by being able to achieve the KPI target (key performance indicator) that has been determined by the company namely advertisement and direct marketing while the event itself is still not achieve leads that have been determined so that the Author advises companies to be able to create an event model that is able to better manage potential customers by giving demonstrations on all products and user testimonials of Jojonomic products so that prospective customers have the trust that Jojonomic products are the best products.

2. Using Integrated Marketing Communication with the 360-Degree Communication Model, a program that can help Jojonomic is expected to be able to increase potential leads by using marketing using Through The Line (TTL) and Below The Line (BTL) targeting the Jojonomic target market. This design strategy aims to increase the company's potential leads by creating Events with the latest concepts, Using LinkedinAds to be able to target directly to the target market and also add women to the target of this Advertising because many women have apprenticed to important positions in the company, making content marketing important because using content marketing is able to encourage prospective customers to find out more information and have the possibility to use Jojonomic products, sponsorship events have a great influence on the growth of the company despite using large funds but the benefits to be received by the company will be greater than brand awareness, sales volume, to potential leads. To determine the effectiveness of this activity, it is also accompanied by a timeline and budget that will be used during this activity and the calculation of key performance indicators.

\section{REFERENS}

D'Amico Heather.(2015). THE 6M'S OF MASTERING YOUR INTEGRATED MARKETING CAMPAIGN. (07-28-2019) dari https://www.carnegiedartlet.com/blog/the-6-ms-of-masteringyour-integrated-marketing-campaign/

Chishti, S., \& Barberis, J. (2016). The FinTech Book. https://doi.org/10.1002/9781119218906

Järvinen, J., \& Taiminen, H. (2016). Harnessing marketing automation for B2B content marketing. Industrial Marketing Management, 54, 164-175. doi:10.1016/j.indmarman.2015.07.002

Leong, C., Tan, B., Xiao, X., Tan, F. T. C., \& Sun, Y. (2017). Nurturing a FinTech ecosystem: The case of a youth microloan startup in China. International Journal of Information Management, 37(2), 92-97. https://doi.org/10.1016/j.ijinfomgt.2016.11.006

Lu, L.-C et al (2014) Customer attitude toward blogger's sponsored recommendations and purchase intention: the effect of sponsorship type, product type, and brand awareness

Mirosława Pluta-Olearnik (2018). Minib28 marketing of scientific and research organization

Muhanji, Evinah Mbayisi and Ngari, Boaz (2015). Influence of Marketing Communication and Sales Performance of Commercial Banks in Kenya.

Tomalieh, E. F. (2016). The Impact of Events Sponsorship on Attendee's Purchase Intention: The Mediating Role of Brand Image. International Journal of Business and Management, 11(8), 162.doi:10.5539/ijbm.v11n8p162

Tsikirayi, Catherine Mazwi R et al (2013) Impact of integrated marketing communication mix (IMCM) in small to medium enterprises (SMEs) in Zimbabwe as a marketing tool

Adetunji Raji Ridwan, Nordin Shahrina Md, Noor Shuhaida Md (2014) The Implementation of Integrated Marketing Communication (IMC) Principles in Branding and Advertising: A Conceptual Exploration 